\title{
CRYSTALLIZATION SUPPORT TUBE IN A LABORATORY FURNACE
}

\author{
Aco Janićijević, Nebojša Danilović* \\ University of Belgrade, Faculty of Technology and Metallurgy, Karnegijeva 4, \\ 11000 Belgrade, Serbia \\ University of Kragujevac, Faculty of Sciences, Radoja Domanovica 12, \\ 34000 Kragujevac, Serbia \\ *Corresponding author; E-mail: nebojsadanilovic01@gmail.com
}

(Received March 30, 2018; Accepted April 24, 2018)

\begin{abstract}
Design of modular, simple to build and handle air cooler ("crystallization support tube") installed in a laboratory tube furnace is presented. The setup allows easy regulation and simultaneous crystallization tests of different temperature gradients, shapes of crystallization fronts and rate intervals in crucibles and Tamman test tubes, enabling fast studies of obtaining crystals. The relationship between the crystallization parameters has been derived and numerically analyzed. This method can also be applied in crucible or tube furnaces.
\end{abstract}

Keywords: crystal growth, air cooler, laboratory furnace.

\section{INTRODUCTION}

In principle, monocrystals can be obtained by crystallization from solid, liquid or gas phases. Within these possibilities a number of methods have been developed (TARJAN and MATRAI, 1972; WILKE and BOHM, 1988). Selection of the proper method for growing monocrystals of a given substance depends upon many factors, primarily on the nature of the substance and its physicochemical properties, quality desired and intended application of crystals as well as on available laboratory possibilities.

In many cases, monocrystals are obtained by growing from the melt, which is in essence a controlled cooling growth; in comparison with other methods for monocrystal preparation this method is simpler and easilier to control. When crystals are growing from the melt a higher crystallization rate than by other methods can be achieved. With the exception of crystal growth from water solutions, this process has been most thoroughly investigated from the technical standpoint. Crystal growth from the melt is widely applicable (ČABRIĆ and JANIĆIJEVIĆ, 2012).

The preparation of crystals of good quality (containing a small concentration of impurities and defects) requires crystallizing substances of a high purity, vacuum or an inert atmosphere (vacuum is not suitable if the substance has a high vapour pressure at the melting 
temperature), crucibles made of materials which do not react chemically with the melt, a high temperature stabilization in the furnace and the absence of mechanical shocks (TARJAN and MATRAI, 1972).

\section{APPARATUS}

In the previous papers (CABRIC et al., 2011; CABRIC et al., 2013), models of air coolers in a laboratory tube furnace, for regulating the crystallization fronts and rates in a several crucibles and Tamman test tubes are shown. In this paper, we show the development and improvement of the interior and exterior of the coolers, with movable cold plugs and cold thresholds (Fig. 1). The improved coolers are simple to build and handle. The coolers allows easy regulation of simultaneous crystallization tests of different number of crystallization parameters, with the purpose of obtaining single crystals from a family of newly synthesized compounds with a layered crystal structure (WILKE and BOHM, 1988) in a laboratory tube furnace.

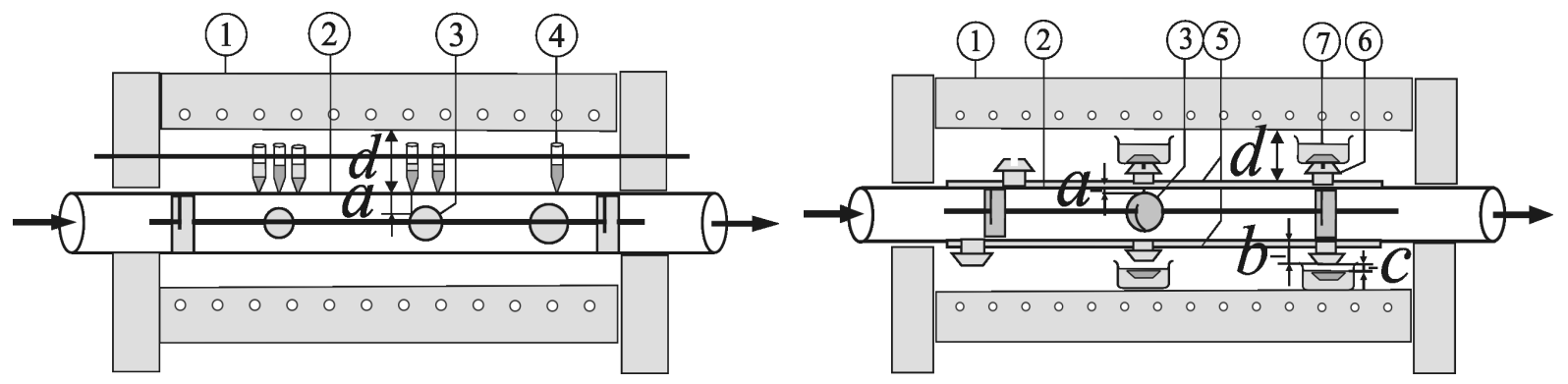

Figure 1. Air cooled tube in tube furnace: (1) laboratory tube furnace, (2) crystallization support tube, (3) movable cold thresholds, (4) Tamman test tube, (5) slide bar, (6) movable cold plug, (7) crucible.

\section{BASIC EQUATIONS FOR COMPUTATIONS}

The rate of melt solidification depends upon extracting the latent heat of solidification. For a time interval t, a crystal layer of thickness $\delta$ is formed (Fig. 1). During the formation of an elementary crystal layer of thickness $d \delta$ per unit area, the amount of heat released is $L \rho d \delta$ ( $\mathrm{L}$ denotes the latent heat of solidification and $\rho$ the crystal density); the latter is being extracted through the cooler for a time interval dt. On this basis the following equation may be written (ČABRIĆ et al., 1990):

$$
L \rho d \delta=\frac{\Delta T}{1 / \alpha+b / k_{b}+\delta / k} d t
$$

where $\Delta \mathrm{T}$ denotes the difference between the temperature of the melt and that of the air stream, $\alpha$ is the coefficient of heat transfer from the cooler wall to the air stream, $b$ denotes the plug height, $\mathrm{k}_{\mathrm{b}}$ designates the heat conductivity of the plug and $\mathrm{k}$ is the heat conductivity of the crystal. Introducing the parameter $a=1 / \alpha+\mathrm{b} / \mathrm{k}_{\mathrm{b}}$ and transforming equation (1) we obtain

$$
R=\frac{d \delta}{d t}=\frac{\Delta T}{a L \rho(\delta / a k+1)}
$$

The quotient $\mathrm{d} \delta / \mathrm{dt}$ denotes the rate of crystal layer growth which is usually represented by the symbol $\mathrm{R}$; it is greatest at the beginning $(\delta=0)$ and decreases with increasing thickness of the solidified layer. 
Integration of equation (2) within the limits from 0 to $\delta$ and from 0 to $t$, and solving from $\delta$ gives the relation

$$
\delta=a k\left[\left(1+\frac{2 \Delta T}{a^{2} L \rho k} t\right)^{1 / 2}-1\right]
$$

by means of which one can calculate also the time needed for the solidification front to reach the surface of bottom of the melt.

\section{RESULTS AND DISCUSSION}

In accordance with equation (2), we obtained numerical values of crystallization rate $R$ in function of the difference between the temperature of the melt and that of the airstream $\Delta T$, in the case of tin (Sn) (Fig. 2). Also, in accordance with equation (3), we obtained numerical values of thickness of crystal layer $\delta$ as a function of the height of the plug $b$, in the case of tin (Sn) (Fig. 3).

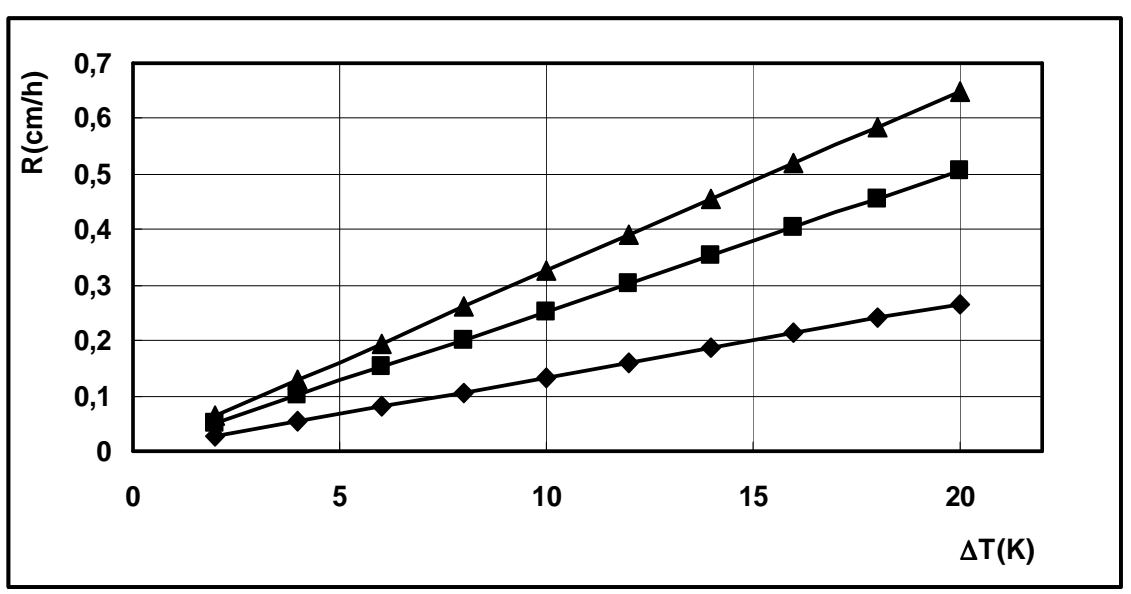

Figure 2. Crystallization rate $R$ as a function of the difference between the temperature of the melt and that of the airstream $\Delta T$ in the case of tin $(\mathrm{Sn}): L=58200 \mathrm{~J} / \mathrm{kg}, \rho=7300 \mathrm{~kg} / \mathrm{m}^{3}, k_{b}=0.756 \mathrm{~W} / \mathrm{mK}$, $k=59.8 \mathrm{~W} / \mathrm{mK}, \delta=2 \mathrm{~cm}, b=1 \mathrm{~cm}-\alpha=20 \mathrm{~W} / \mathrm{m}^{2} \mathrm{~K}-\alpha-\alpha=50 \mathrm{~W} / \mathrm{m}^{2} \mathrm{~K}-\boldsymbol{\Lambda}-\alpha=80 \mathrm{~W} / \mathrm{m}^{2} \mathrm{~K}$.

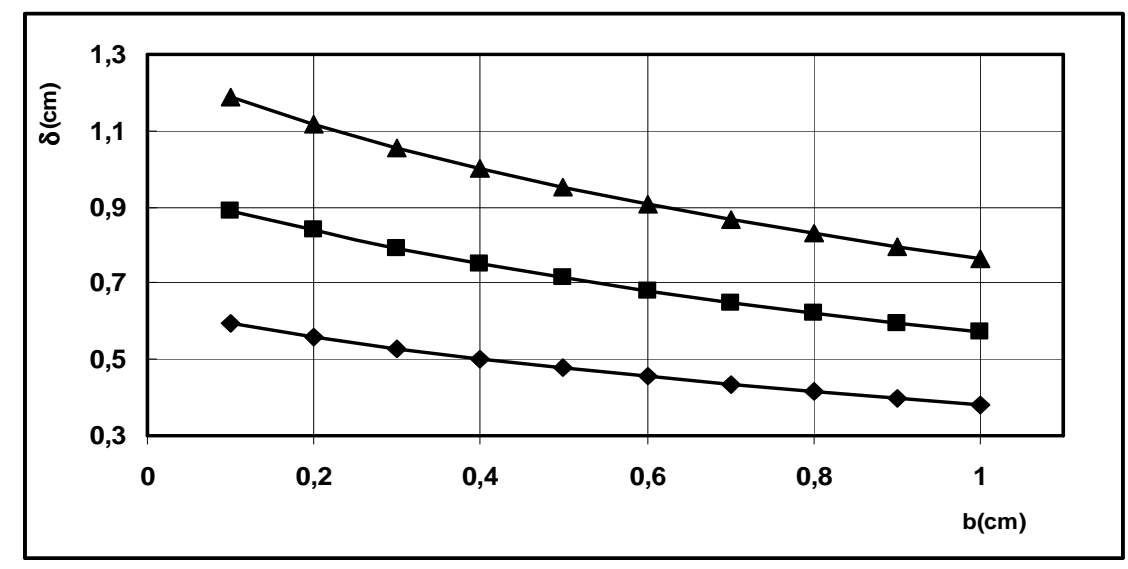

Figure 3. Thickness of crystal layer as a function of the height of the plug $b$, in the case of tin (Sn): $L=58200 \mathrm{~J} / \mathrm{kg}, \rho=7300 \mathrm{~kg} / \mathrm{m}^{3}, \alpha=50 \mathrm{~W} / \mathrm{m}^{2} \mathrm{~K}, k_{b}=0.756 \mathrm{~W} / \mathrm{mK}, k=59.8 \mathrm{~W} / \mathrm{mK}, t=1.5 \mathrm{~h}$, $-\Delta T=10 \mathrm{~K},-\boldsymbol{-}-\Delta T=15 \mathrm{~K},-\boldsymbol{\Lambda}-\Delta T=20 \mathrm{~K}$. 
The crystallization rate interval in each crucible and Tamman test tube is regulated by the cross section of the airflow $a$ (Fig. 1) and by the difference between the temperature of the melt and that of the airstream $\Delta T$ (Fig. 2). The crystallization rate interval in crucibles can also be regulated by the plug height $b$ (Fig. 1 and Fig. 3) and the distance of the plug head from the surface of the melt $c$ (in the crucibles below the cooler) (Fig. 1). The temperature gradient is regulated by the distance $d$ (Fig. 1). Plugs of various shapes and dimensions can be mounted on the air-cooled tube and thus simultaneously tested. By varying the internal and external shapes and dimensions of the cooler, a set of crystallization tubes can be modeled for tests in a wider range of crystallization parameters and substances. The shapes and dimensions of crystallization front in crucibles can be regulated by the plug fronts, i.e. plug heads (Fig. 1).

\section{CONCLUSIONS}

The improved cooler ("crystallization support tube") is simple to build and handle, and enable mounting different number of crucibles and Tamman test tubes. This enables easy regulation and simultaneous crystallization tests of different number of crystallization parameters, with the purpose of obtaining single crystals from a family of newly synthesized compounds with a layered crystal structure in a laboratory tube furnace.

The cooler can be modified and installed into a crucible furnace. Also, the cooler can be applied in a chamber furnace.

\section{Acknowledgments}

In memoriam to Professor Branislav Čabrić. We are grateful to him for his ability to always create positive work atmosphere.

\section{References:}

[1] Cabric, B., Danilovic, N., Janicijevic, A. (2011): Tube for obtaining crystals in a laboratory furnaces. Instruments and Experimental Techniques 54: 282-283. doi: 10.1134/S0020441211010210

[2] Cabric, B., JaniciJevic, A., Danilovic, N. (2013): Crystallization tests bench. Crystallography Reports 58 (1): 198-200. doi: 10.1134/S1063774513010161

[3] ČABRiĆ, B., JANiĆIJEviĆ, A. (2012): New Class of Apparatus for Crystal Growth from Melt. In: Kolesnikov, N., Borisenko, E. (eds.) Modern aspects of bulk crystal and thin film preparation. InTech-Open Acess Publisher: 3-24.

[4] ČAABIĆ, B., ŽIŽIĆ, B., NAPIJALO, M.LJ. (1990): An apparatus for crystal growth in the undergraduate laboratory. Eur. J. Phys. 11: 233-235. doi: 10.1088/0143-0807/11/4/007

[5] TARJAN, I., MATRAI, M. (eds.) (1972): Laboratory manual on crystal growth. Akademiai Kiado, Budapest: 221-238 pp.

[6] WILKe, K.-Th., BoHM, J. (1988): Kristallzüchtung. Verlag Harri Deutsch, Thun, Frankfurt / Main: 591-647 pp. 